\title{
Article
}

\section{Digital Facility Layout Planning}

\author{
Mirco Peron ${ }^{1, *} \mathbb{B}$, Giuseppe Fragapane ${ }^{1}\left[\mathbb{D}\right.$, Fabio Sgarbossa ${ }^{1} \mathbb{D}$ and Michael Kay ${ }^{2}$ \\ 1 Department of Mechanical and Industrial Engineering, Norwegian University of Science and Technology, \\ 7031 Trondheim, Norway; giuseppe.fragapane@ntnu.no (G.F.); fabio.sgarbossa@ntnu.no (F.S.) \\ 2 Edward P. Fitts Department of Industrial and Systems Engineering, North Carolina State University, Raleigh, \\ NC 27607, USA; kay@ncsu.edu \\ * Correspondence: mirco.peron@ntnu.no;
}

Received: 10 March 2020; Accepted: 18 April 2020; Published: 20 April 2020

check for updates

\begin{abstract}
In recent years, companies have increased their focus on sustainability to achieve environmental-friendly improvements, to manage pressures from society and regulations, and to attract customers that appreciate sustainability efforts. While companies have mainly aimed short-term/operational improvements, long-term improvements are difficult to reach. One of the fundamental, strategical decision-making processes for a company is facility layout planning. The layout of a facility can have a significant impact on daily operations. Aiming for the goal of sustainability, a dynamic layout decision-making process can support in achieving it. However, the technologies used currently enable only the design of a static layout due to the time-consuming operations involved. In this paper, the introduction of emerging technologies such as 3D mapping, Indoor Positioning System (IPS), Motion Capture System (MoCap), and Immersive Reality (IR) for dynamic layout planning are assessed and discussed. The results obtained clearly demonstrate that the usage of these technologies favor a reconfigurable layout, positively affecting all the three pillars constituting the sustainability concept: the costs involved are reduced, social aspects are improved, and the environment is safeguarded.
\end{abstract}

Keywords: facility layout planning; digitalization; 3D mapping; indoor positioning system; motion capture system; immersive reality; performance analysis

\section{Introduction}

Facility layout planning has long been an essential component in the design of production systems. The most significant development in providing a practical quantitative approach to layout problems was the introduction of CRAFT in 1963 [1]. Prior to that, most approaches to the layout problem were non-quantitative, providing a series of checklists to be used as part of the layout process (see, e.g., [2]). CRAFT provided a means to heuristically solve the layout problem modeled as a quadratic assignment problem with area constraints. As computer capability increased, it became feasible to use more computationally intensive heuristic procedures and to consider both static and dynamic aspects of a layout [3]. Recently, extensions, including the multi-floor facility layout problem [4] and the impact of layout on the lifecycle of production systems [5], have been considered. Hosseini-Nasab et al. [6] have presented a classification of facility layout problems that reflects recent research.

Although some of the most recent work in facility layout reflects the fact that more efficient computational procedures continue to be developed and applied to the layout problem, more of the recent work has reflected the changing nature of new production systems (see, e.g., [7]). Production systems today are frequently designed to be reconfigurable and adaptable, and integrated into advanced material handling systems. Often, they need to be flexible and scalable enough to be cost-effectively modified in response to changing demand. All of these changes have resulted in the need to be able to 
incorporate emerging technologies, in particular, recent developments in sensor technology, to be able to automatically collect data concerning a production system so that it can be effectively utilized in an ongoing process of facility re-layout.

The increase in e-commerce has already significantly impacted warehousing, including both the location and size of new warehouses and their internal layout and operation [8]. The most significant technological development supporting this change has been the ever-increasing use of Kiva-type mobile robots. These robots allow both the layout and operation of the warehouse to be dynamically changed because the robots provide both material storage and transport that can be controlled via software. Warehousing has always served as an excellent initial testbed for new technologies that only later are incorporated into more general facility layouts. This is primarily due to the structured environment of the warehouse and the fact that most of the storage locations in a warehouse do not interact with each other. Traditionally, this has allowed the warehouse location problem to be easily solved as a linear assignment problem as opposed to the more difficult quadratic assignment problem used for the general facility layout problem. More recently, the ability to continuously track mobile robots in a warehouse has allowed more dynamic procedures to be used to continually update the layout (i.e., the location of the robot's storing material) based on changing demand and supply conditions; for example, the original Kiva robot system (now Amazon Robotics) uses multi-agentbased control to continually re-layout a warehouse via a bidding procedure.

The theory and scientific contributions available in the literature concerning facility layout planning have been developed and validated several times, and systematic layout planning procedures were introduced many years ago. However, the majority of the research contributions have been focused on the development of methodologies for optimal facility layout. Moreover, no research has been carried out that considers the digitalization of these procedures so that a concurrent engineering approach could be applied in order to make them more efficient and less time-consuming. Additionally, while sustainability aspects of layout planning have not been investigated in the literature to date, new digital technologies are demonstrating their potential benefits in improving sustainability in industry. This paper is the first to envision how emerging digital technologies can be used to provide the basis upon which dynamic procedures can be developed to create more general and sustainable facility layouts.

This work shows for the first time how emerging digital technologies can support a concurrent engineering approach in facility layout planning. Concurrent engineering is widely used in designing and development of new products, where the different phases or stages of the design process run simultaneously instead of sequentially. This is possible thanks to digital tools, such as CAD, CAM, and simulation software. In the same way, the facility layout planning can be supported by emerging technologies able to run simultaneously various phases of the process with more accurate information available in digital format. This type of approach will become ever more critical as companies need to almost continuously consider changes to their facility layout to best provide goods and services, the demand for which is also changing at an ever faster pace. The problem of tracking the different layout elements for the general layout problem is very complicated because the flows of material and people in the general layout problem are inherently three-dimensional, necessitating a very complex sensing task. In addition, spatial complexity influences the level of spatial detail upon which technologies perform, affecting their function and effectiveness [9]. While it is thus too early to expect that emerging technologies will be able to completely automate the general layout problem, the ability to sense the environment and automatically store material and personnel flows will allow the most critical layout elements to be dynamically reconsidered on an ongoing basis.

This represents a benchmark for the development of sustainable facilities, where sustainability has to be considered as the combination of three pillars, namely environmental, social, and economic [10-12]. In a scenario where market needs and social desires change continuously, a company has thus to face constant transformations to be continuously sustainable, especially in the production area, which is, however, usually designed for medium/long-term periods due to the difficulties and time-consuming 
operations behind layout planning procedures. In this regard, the implementation of emerging technologies can be beneficial, allowing faster and more frequent layout planning studies due to their increased level of automation and accuracy. This topic is still underexplored, and the final contribution of this paper is an overview of the possibilities provided by the new technologies with respect to the layout planning from a sustainability perspective. Summarizing, the present paper wants to answer the following research questions:

- What digital technologies can support facility layout planning?

- How can each technology be used and implemented in facility layout planning?

- What is the impact of emerging technologies on the three pillars of sustainability in facility layout planning?

In the following section, the research starts with an overview of the layout planning procedures in order to analyze the areas of improvement that digital technologies can impact. Then, a detailed description and analysis of the emerging technologies that can be implemented is given in order to answer the first research question. In Section 3, the research methodology highlights the pros of the improvements achievable by implementing these technologies thanks to some examples of their application in the Logistics 4.0 Lab at NTNU (Norway). In this section, it is also discussed how each technology can be used and implemented, as asked by the second research question. The discussion section, then, presents the enhanced sustainability achievable through the implementation of these technologies with respect to the three pillars (environmental, social, and economic) in order to answer the third research question, and finally, the conclusions section is reported.

\section{Theoretical Background}

\subsection{Layout Planning}

Facility layout planning is the arrangement of all equipment, machinery, and furnishings within a building envelope after considering the various performance objectives. Thereby, the design process can be divided into department, machine, and workstation levels (Table 1). While the layout of the department level shows the location, shape, and size of each planning department, the machine level represents and describes a more detailed layout in which the exact location of all equipment, workbenches, and storage areas are within a department. On the workstation level, the detailed arrangement of tools, bins, rigs, parts, etc., within a single workstation is expressed and shown. All three levels need to be created, analyzed, and evaluated in order to achieve high performance and sustainable goals.

Different procedures such as layout planning or systematic layout procedure, etc., and multi-objective formulation of the facility layout problem have supported to define the optimal facility layout, proposing the following five-step layout planning procedures (Figure 1) [13,14].

Step 1-Activities

The activities step consists of input data and identifying activity areas to create a foundation for layout planning. The following five elements that should be examined include:

P-Product (What): The product element includes the raw materials, purchased parts, formed or treated parts, the finished goods, and or service items supplied or processed This element is the key factor that affects the composition and relationship of all facilities, equipment categories, and material handling.

Q-Quantity (How much): The quantity element indicates the number of goods or services produced, supplied, or used. All the information is provided by production statistics such as piece, weight, volume, and price. This element affects the layout scale, equipment amount, handling workload, and construction area. 
$\mathrm{R}$-Route (How): The route element relates to the process, its equipment, its operations, and its sequence. It affects the relationship among every work unit, material handling route, and storage location.

S-Supporting service (With what): The supporting service element includes things such as maintenance, machine repair, tool room, toilets, locker rooms, cafeteria, first aid, offices, and shipping and receiving. The service department supports the production system and somehow reinforces the production efficiency. The supporting service often uses more floor area than the producing departments themselves.

T-Time (When): The element of time refers to when, how long, how often, how soon the products will be produced. According to the time required, the amount of equipment, the required area, and the number of staff can be estimated.

In addition to PQRST, analysis of the activities or activity areas included in the layout need to be identified. An activity or activity area can also be referred to as equipment or departments.

\section{Step 2-Relationships}

The relationships step consists of the flow of materials, activity relationships, and the relationship diagram. The goal of the material flow analysis is to find the most effective sequences of moving materials through the system. Process or flow charts can be used to analyze the material movement within the layout. A from-to chart can be used to show quantitative data such as distance and frequency of movement between departments. Other than the flow of materials, qualitative relationships should be considered for best practice. The activity relationship chart considers these qualitative factors by showing the degree of importance of having each department located adjacent to each other. This analysis is usually performed through stakeholder consultations. The relationship diagram takes the information from the flow of materials analysis and or the activity relationship chart and turns it into a graphic visualization of desired closeness among activity areas.

Step 3-Space

The space step considers the space requirements, space availability, and the space relationship diagram. Thereby, the requirements are focused on the necessary production parameters such as staff, equipment, and other factors from theoretical analysis. Space availability is about the actual facility and where the different work units should be placed. The space relationship diagram is an extension of the relationship chart in which the nodes are now represented as blocks proportional to the calculated space of the departments. It is perhaps the single most effective aid to layout planning.

\section{Step 4-Adjustments}

The adjustments step includes modifications, limitations, and the alternative layouts. Regarding modifications, certain factors that might affect the following implementation of the layout should be considered. Such factors include site conditions and surroundings, building features, safety, and personnel requirements. Limitations are factors that impose constraints on the planning. For each idea, there is a set of practical limitations that must be weighed. One of the most important limitations is the question of cost-saving and available investment money. After the modifications and limitations, the planner should end up with about two to five alternative layout plans.

\section{Step 5-Evaluation}

Quantitative approaches of quadratic assignment problem, mixed integer programming, and graph theory have supported to mathematical model the facility layout problem and find exact or near-optimal solutions. The objectives functions have been translated into qualitative and quantitative layout evaluation criteria, and the most common objectives have been [15]:

- Optimize capital investment (initial investment, installation fixed costs, start-up costs, annual operating costs, maintenance costs, return on investment, payback period) 
- Optimize space utilization

- Optimize flow (materials, personnel, and information)

- Optimize handling (e.g., minimize the cost of materials handling)

- Optimize the use of equipment

According to [16], the most commonly used quantitative criterion for evaluating a manufacturing facility layout is to minimize the materials handling cost, which is a quantitative factor. Qualitative factors such as plant safety, the flexibility of layout for future design changes, noise, and aesthetics have been considered in recent years more and more [17].

Table 1. Layout planning.

\begin{tabular}{|c|c|c|c|c|}
\hline \multirow{2}{*}{$\begin{array}{l}\text { Pattern of } \\
\text { Procedures }\end{array}$} & \multicolumn{3}{|c|}{ Input Data } & \multirow{2}{*}{ Output Data } \\
\hline & Department Level & Machine Level & Workstation Level & \\
\hline & - P-Q Data Sheet & - Operation process chart & - Bill of materials & List of \\
\hline 1. Activities: & - Routing data & - Flow process chart & - Precedence Diagram & Activity \\
\hline PQRST Analysis & - Service requirements & - Multi-product process chart & - Operation process chart & Areas \\
\hline 2. Relationships: & - Operation Process Chart & & & \\
\hline $\begin{array}{l}\text { Flow of Materials } \\
\text { and Activity }\end{array}$ & $\begin{array}{l}\text { - Multi-product Process Chart } \\
\text { - From-To Chart }\end{array}$ & - Line-feeding flow chart & - Precedence Diagram & $\begin{array}{l}\text { Relationship } \\
\text { Diagram }\end{array}$ \\
\hline Relationships & - Relationship Survey & & & \\
\hline $\begin{array}{l}\text { 3. Space: Space } \\
\text { Requirements and } \\
\text { Availability }\end{array}$ & $\begin{array}{l}\text { - Survey of current space assigned } \\
\text { - Machinery and Equipment Area and } \\
\text { Features Sheet } \\
\text { - Office Layout Requirements Data } \\
\text { Space Requirements Converting form }\end{array}$ & $\begin{array}{l}\text { - Machinery and Equipment } \\
\text { Area and Features Sheet } \\
\text { - Office Layout } \\
\text { Requirements Data }\end{array}$ & $\begin{array}{l}\text { - Components and Tools } \\
\text { Area }\end{array}$ & $\begin{array}{l}\text { Space } \\
\text { Relationship } \\
\text { Diagram }\end{array}$ \\
\hline $\begin{array}{l}\text { 4. Adjustment: } \\
\text { Modifications and } \\
\text { Limitations }\end{array}$ & $\begin{array}{l}\text { - Scaled and grid-lined templates of } \\
\text { activity areas }\end{array}$ & $\begin{array}{l}\text { - Scaled equipment } \\
\text { templates } \\
\text { - Models and renderings } \\
\text { - Elevation drawings }\end{array}$ & $\begin{array}{l}\text { - CAD prototype } \\
\text { - Physical mock-up }\end{array}$ & $\begin{array}{l}\text { Alternative } \\
\text { Layouts }\end{array}$ \\
\hline 5. Evaluation & $\begin{array}{l}\text { - Layout comparison based on cost, } \\
\text { space, flow, handling, use of } \\
\text { equipment and others }\end{array}$ & $\begin{array}{l}\text { - Layout comparison based } \\
\text { on cost, space, flow, } \\
\text { handling, use of equipment } \\
\text { and others }\end{array}$ & $\begin{array}{l}\text { - Layout comparison } \\
\text { based on cost, space, } \\
\text { flow, handling, use of } \\
\text { equipment and others }\end{array}$ & $\begin{array}{l}\text { Selected } \\
\text { Layout }\end{array}$ \\
\hline
\end{tabular}

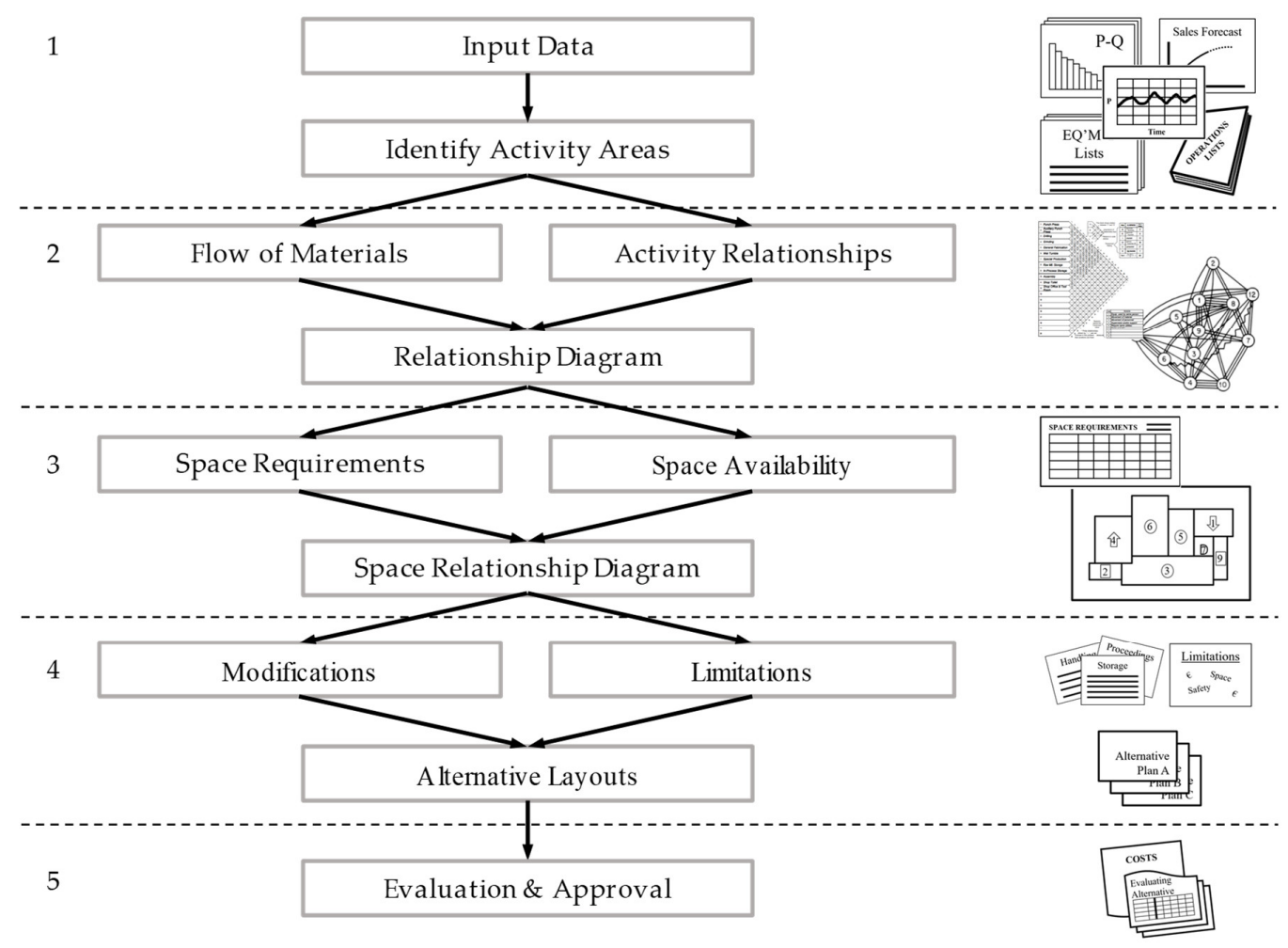

Figure 1. Systematic Layout Planning and its tools. 


\subsection{Digital Technologies for Layout Planning}

\subsubsection{D Mapping}

Three-dimensional (3D) modeling of an object or environment can be described as the process of starting with data acquisition and ending with a 3D virtual model, visually interactive on a computer [18]. While 3D modeling is often only seen as the process of converting a measured point cloud into a triangulated network or textured surface, it should be seen more as a reconstruction process of objects or the environment. In the past, 3D modeling of objects and the environment has found great interest among researchers in the fields of graphic, vision, and photogrammetric. The growing applicability of digital 3D models has made 3D modeling a crucial and fundamental process in inspection, visualization, navigation, object identification, and classification. For instance, detailed 3D visual models of indoor spaces, from walls and floors to objects and their configurations, can provide extensive knowledge about the environments as well as rich textual information of people living therein and how they interact with the environment. The used technologies for 3D modeling allow contact-free sensing and can thereby acquire relative large-scale data with dense coverage of comparably large areas. Three methods are commonly used to 3D scan and model Infrared scanners, Photogrammetry, and LiDAR (Light Detection and Ranging).

Infrared scanners use infrared or structured light to scan an object. Structured light 3D scanning devices identify distortions in light projected onto the surface and process the information to recreate the object's surface geometry. Photogrammetry, on the other hand, processes the information of several photos of the same object with a minimum overlap of $40 \%$ and an angle variety of 5 to 10 degrees to produce a 3D scan. Comparing and contrasting pixels across a group of photos, photogrammetry matches, estimates, triangulates and evaluates the entire scenes. The photogrammetry method offers a balanced solution between low costs and the resolution of scans. However, the method is depending strongly on the light factor. Reflective surfaces and transparency, glossy, shiny, and surrounding blank of details can strongly decrease the quality of scans.

The LiDAR method bounces laser light off an object or surface to measure distance and depth to form a 3D scan. Thereby, the LiDAR pulses, on average, 400,000 every second and creates a point cloud. The measurement system is often compound of three units: a laser measuring the distances and range of an object or surface, a local reference point which often is GPS, and an initial measurement unit to measure the pitch, roll, and heading of the laser device. One of the major advantages which made the technology as well so popular is the easily dynamic usage and fast acquisition of results. Even though the measuring system is fast-moving, a high density of information can be retrieved.

In production and operations management, the resulting information of the 3D scans have been mainly used for quality control and applied in a large variety of industrial application areas such as automotive manufacturing for car body deformation measurement, control of supplier parts, monitoring and control of production machinery and processes [19]. The photogrammetric measuring system has further supported to improve the finite element simulation. Verifying and comparing measured data of stamped metal sheet parts by photogrammetry and the results of the simulation have enhanced the springback analysis and critical strain distributions utilizing visioplasticity [20]. 3D modeling has been applied more in the construction industry both for planning and control purposes. The integration of Building Information Modeling has enabled real-time quality control to identify early defects or deviations and, thus, supported reducing project time and cost overrun [21]. Recently, unmanned aerial vehicle and operations have supported to plan more efficiently. Inaccurate information regarding the terrain in construction projects represents a major challenge. Precise and most actual 3D models of the environment have enabled to plan and place working equipment to their needs, and increased the cost-effectiveness of construction projects [22]. 


\subsubsection{Indoor Positioning System (IPS)}

An indoor positioning system (IPS) is defined as a system that permits a mobile device to determine its position, and that renders this position available for position-based services [23]. These position-based services can bring benefits in several environments, such as hospitals, where the position of the equipment needs to be known to efficiently use the medical resources, supermarkets, where the customers want to know the fastest path to reach the desired products; and large museums, where tourists are interested in knowing the location of the artworks they are interested in [24]. In the last years, IPS has gained interest also in the industrial field [25]. Logistic processes are those that can benefit the most from this system. In fact, due to the necessity of handling huge amount of products with very short lead times, logistics has to eliminate all the inefficiencies, such as delays in the searching of the required product in the warehouse, errors in the storage or in the picking of an item, and waste of time during the traveling of carts and operators. As stated by Curran et al. [26], there are several available techniques to identify in real-time the material's location and flow within a warehouse depending on the required performances, i.e., there is not a single best solution that is suitable for each scenario. Therefore, in the last years, different types of IPSs have been introduced, depending on the desired level of accuracy, coverage area, robustness, scalability, cost, and complexity [23]. They can use one or several positioning techniques (i.e., triangulation, fingerprinting, proximity and vision analysis $[27,28]$, but the majority leverage on the triangulation method, where, once the coordinates $X$ and $\mathrm{Y}$ of the three reference elements are known, the position can be calculated by using either the length or the directions of the radii [23].

However, the classification of these IPSs is usually not based on the positioning technique that is used but whether they are network-based or not [29] or on the hardware requirements [30]. Another classification can be based on the main medium used to determine the location, which includes infrared (IR) signals, ultrasound waves, vision-based analysis, and radiofrequency.

Infrared positioning systems are one of the most common positioning systems since IR emitters are small, light-weight, the system architecture is easy, and it performs positioning estimation in a very accurate way (accuracy of several millimeters). However, it has some drawbacks. The main limitation is related to the environment of use of this system, as it requires the absence of interferences and obstacles. Nevertheless, this can also be an advantage; the impossibility of the IR beams to penetrate the walls assure the possibility to limit the signal inside a specific room [31]. Other limitations are the high cost of the hardware, the short-range signal transmission between devices, and the interference from florescent light and sunlight [32].

Ultrasound positioning systems use ultrasound signals to measure the distance of a mobile target from a fixed-point receiver. Despite its low cost, the diffusion of this IPS is hampered by low accuracy (several centimeters), short-range (from 2 to 10 meters), and high susceptibility to noise sources.

Vision-based positioning systems are based on the use of fixed or mobile cameras that can cover a large area. The tracked person and/or device do not need to wear or carry any device. Although the cost is low, the low reliability in a dynamic changing environment, the high susceptibility to many interference sources, and the difficulty in tracking several persons and/or devices have hampered its use.

Radiofrequency position systems use radio waves, such as Wi-Fi, Radio Frequency Identification (RFID), and Ultra-Wide Band (UWB). The first system based on Wi-Fi is quite often used to monitor the movements of mobile devices due to its low cost. In fact, Wi-Fi is widely spread inside the buildings, and thus extra software is not required. The accuracy is quite low (between 20 and 40 meters), but it can be improved, increasing the number of access points and adding wireless routers [33]. The second solution is based on RFID as a means of storing and retrieving data through radio waves to an RF compatible integrated circuit [34]. This system can cover large distances and easily travel through walls and human bodies. Moreover, RFID leverage on small and light tags. However, this system needs several infrastructure components in the working area, and they suffer from multi-path distortion of radio signals reflected by walls and obstacles [23]. Finally, UWB technology uses pulses with a 
very short duration (less than $1 \mathrm{~ns}$ ) to overcome the limitation of the multi-path distortion of radio signals affecting RFID systems. In addition, the use of multiple bands of frequencies simultaneously to transmit its own signal, differently from RFID that uses just a single portion of the frequency spectrum, overcome the RFID's line-of-sight requirement and thus, increase the accuracy.

\subsubsection{Motion Capture System (MoCap) and Immersive Reality (IR)}

In the last few years, beginning with the increase in globalization and mass customization, manufacturing systems are facing continuous changes in order to satisfy the market requirements [35-37]. Flexible production and assembly systems are, in fact, required in order to face unpredictable market changes, characterized by a rapid variation of product demands and frequent introduction of new products. In particular, there is the need to vary the layout and the configuration of these systems depending not only on the product that has to be produced but also on the operator that will work in them, considering the human diversity factors (gender, age, body measures, physical capabilities). In fact, particularly in a scenario characterized by an aging workforce [38,39], the performance of production systems is strongly connected to the operators' performance, especially by the ergonomic conditions of the workplace [40]. The occurrence of musculoskeletal disorders (MSDs) due to unnatural positions and dangerous actions of the workers has been shown to have an extremely negative impact on company productivity, product quality, and production costs [41]. Thus, to optimize the production systems, minimization of operators' fatigue and awkward postures is highly needed. In this perspective, Battini et al. [42] developed a framework able to take into account both the technological variables and the ergonomics evaluations to create a comprehensive analysis. Different ergonomic assessment methods have been developed to evaluate awkward postures of operators, and the most common are observational methods, such as OWAS, RULA, REBA, LUBA, OCRA, NIOSH, BORG SCALE and Strain Index [43-45], where the worker's behavior is observed and evaluated observing the operators in the field or replaying videos. However, these methods are time-consuming, and the results are questionable. In this perspective, recent studies have focused on the development of reliable and fast real-time ergonomic assessment methods $[43,46,47]$. Among these, the inertial Motion Capture System (MoCap) is of high interest. Inertial MoCap is a system where inertial measurement units (IMUs) are placed on the body of the operator, and they interact with a personal computer, usually through a Wi-Fi connection, sending the information about joint angles, body segment orientation, and position, and it is preferable to the traditional optical sensors-based MoCap since it does not need a camera and it is more precise in detecting movement [48]. Vignais et al. [46] first introduced this system, placing the IMUs on the upper part of the body of an operator, evaluating the RULA in real-time, and providing simultaneous feedbacks to improve the ergonomics in a case study. This system has been further developed by [43], where a full-body suit with 17 inertial sensors has been used to evaluate material handling activities in a warehouse. In this case, not only real-time ergonomic evaluations were possible, but also real-time evaluations of the time and methods used to perform each task. More recently, the inertial and optical MoCap have been integrated by [49] in a Motion Analysis System (MAS). The MAS was evaluated in an industrial case study of a gearbox assembly process, reporting that the newly-developed system was able to offer the most accurate representation of the body postures and movements, overcoming the drawbacks of the optical MoCap (tracking occlusion) and of the inertial MoCap (joint positional drift over recording time). However, all these systems require the workstations to be built, at least as prototypes, implying high costs (i.e., production or purchase costs of the prototypes, space usage costs, and staff costs).

It is thus clear that the need for understanding and defining earlier in the design process the workstation characteristics to assure productivity and operator's well-being. In this perspective, close attention has been paid to virtual reality (VR), defined as a set of technologies that "allows the users to interact, move, look at, and be immersed in a 3D environment" [50]. In fact, besides its use in design, virtual prototyping, virtual assembly, and training [50-53], VR has recently been integrated with ergonomic analyses $[54,55]$. A step further was made connecting VR with optical and inertial 
motion capture systems. Peruzzini et al. [56] combined an optical full-body MoCap with mixed reality in the ergonomic assessment of a workstation in the pipe industry, and they reported that the quality of the ergonomic assessment was highly improved compared to that obtained using Delmia V5-6R2016 desktop simulations, and it was much faster. The limitation of the presence of real objects in the mixed reality and of the optical MoCap has been overcome in [57], where the VR-Ergo Log system has been introduced. A head-mounted display (HMD) is used to immerse the operator in an environment reproducing the reality under study, and the ergonomic analysis is carried out in real-time using 31 IMUs placed on a full body suit, including the hands, which guarantees the precision in the tracking of movements.

\section{Results}

The emerging technologies reported in Section 2.2. provide the opportunity to digitalize and improve the facility layout planning procedure. Due to their intrinsic characteristics and properties, each technology is suitable for the implementation only in some levels of the layout (i.e., department, machine, and workstation), and, in particular, only in some of the steps of the layout planning procedure, as discussed here and summarized in Table 2. In the following we report the results obtained from the application of these technologies in the Logistics4.0 Lab at NTNU (Norway).

Table 2. Emerging technologies in the layout planning.

\begin{tabular}{|c|c|c|c|c|}
\hline $\begin{array}{l}\text { Pattern of } \\
\text { Procedures }\end{array}$ & Department Level & Machine Level & Workstation Level & Form of Output \\
\hline 1. Activities & $\begin{array}{c}\text { IPS: } \\
\text { - Real-time information } \\
\text { about Route and Quantity of } \\
\text { the products }\end{array}$ & $\begin{array}{c}\text { IPS: } \\
\text { - Fast, easy and detailed } \\
\text { Operation process chart } \\
\text { - Real-time Flow process chart } \\
\text { - Real-time Line balance }\end{array}$ & $\begin{array}{l}\text { MoCap and IR / IPS: } \\
\text { - Fast, easy and detailed } \\
\text { Operation process chart }\end{array}$ & $\begin{array}{l}\text { List of Activity } \\
\text { Areas }\end{array}$ \\
\hline 2. Relationships & $\begin{array}{c}\text { IPS: } \\
\text { - Fast, easy and detailed } \\
\text { Operation Process Chart and } \\
\text { From-To Chart } \\
\text { - Congestion phenomena } \\
\text { evaluation }\end{array}$ & $\begin{array}{c}\text { IPS: } \\
\text { - Fast, easy and detailed } \\
\text { Relationship Chart } \\
\text { - Congestion phenomena } \\
\text { evaluation }\end{array}$ & $\begin{array}{c}\text { IPS: } \\
\text { - Fast, easy and detailed } \\
\text { Spaghetti Chart }\end{array}$ & $\begin{array}{l}\text { Data-Driven } \\
\text { Relationship } \\
\text { Diagram }\end{array}$ \\
\hline 3. Space & $\begin{array}{c}\text { 3D mapping: } \\
\text {-Fast, easy and detailed } \\
\text { Activity Areas and Features } \\
\text { Sheet } \\
\text { - Fast, easy and detailed } \\
\text { Survey of current space } \\
\text { assigned } \\
\text { - Connection/relations } \\
\text { between different Areas }\end{array}$ & $\begin{array}{c}\text { 3D mapping: } \\
\text { - Fast, easy and detailed } \\
\text { Activity Areas and Features } \\
\text { Sheet } \\
\text { - Fast, easy and detailed Survey } \\
\text { of machine's position } \\
\text { - Connection/relations between } \\
\text { different Areas } \\
\text { - Position of movable } \\
\text { equipment }\end{array}$ & $\begin{array}{l}\text { 3D mapping:- Fast, easy } \\
\text { and detailed collection of } \\
\text { space info about existing } \\
\text { workstation to build 3D } \\
\text { model for virtual } \\
\text { mock-up }\end{array}$ & $\begin{array}{l}\text { Digital 3D Space } \\
\text { Relationship } \\
\text { Diagram }\end{array}$ \\
\hline 4. Adjustment & $\begin{array}{l}\text { 3D mapping: } \\
\text { - Fast, easy and detailed } \\
\text { image of Block Layout }\end{array}$ & $\begin{array}{c}\text { 3D mapping: } \\
\text { - Fast, easy and detailed Layout } \\
\text { image } \\
\text { - Models and renderings }\end{array}$ & $\begin{array}{c}\text { MoCap and IR: } \\
\text { Detailed Workstation } \\
\text { Simulations: } \\
\text { - Virtual prototype } \\
\text { - Virtual mock-up } \\
\text { - Real-time ergonomic } \\
\text { evaluations }\end{array}$ & $\begin{array}{l}\text { Digital 3D } \\
\text { Alternative } \\
\text { Layouts }\end{array}$ \\
\hline 5. Evaluation & - & - & - & Selected Layouts \\
\hline
\end{tabular}

3D mapping technologies are particularly attractive for step 3 and step 4 of the layout planning procedures at the department and machine levels, but also for workstation level, where information about space and its utilization is needed (Table 2). The commonly used techniques to provide the required information to perform step 3 and step 4 consist of 2D drawings manually made by the analysts (Figure 2b). Specifically, the analyst has to measure the space assigned to a determined area and/or the overall dimensions of the machines/equipment, leading to high consumption of time, especially if precise information is needed, and this has to be carried out every time an update is needed. By implementing 3D mapping technologies, these drawbacks can be easily overcome since most of the work is carried out by the software processing the images, resulting in a high saving of 
time that facilitates constant updates of the layout. In such a way, more precise information is easily obtained concerning the position of movable equipment (Figure 2a). Furthermore, a level of detail including information about the connections/relationships between different areas and/or machines that would have required extra time with $2 \mathrm{D}$ drawing is easily obtained with $3 \mathrm{D}$ technologies, also providing immediate information about the position of the input and output of machines (Figure 2c).

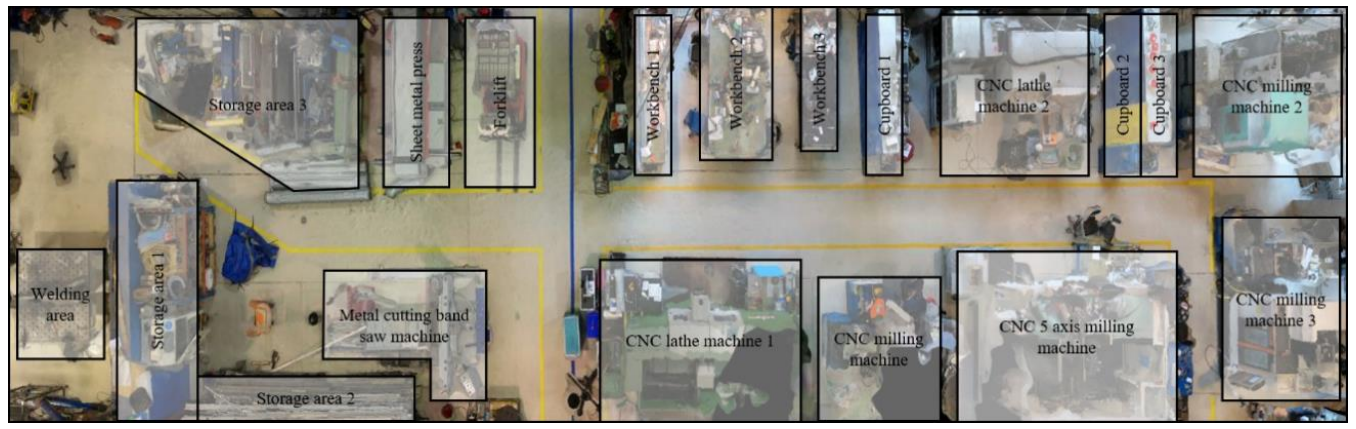

(a)

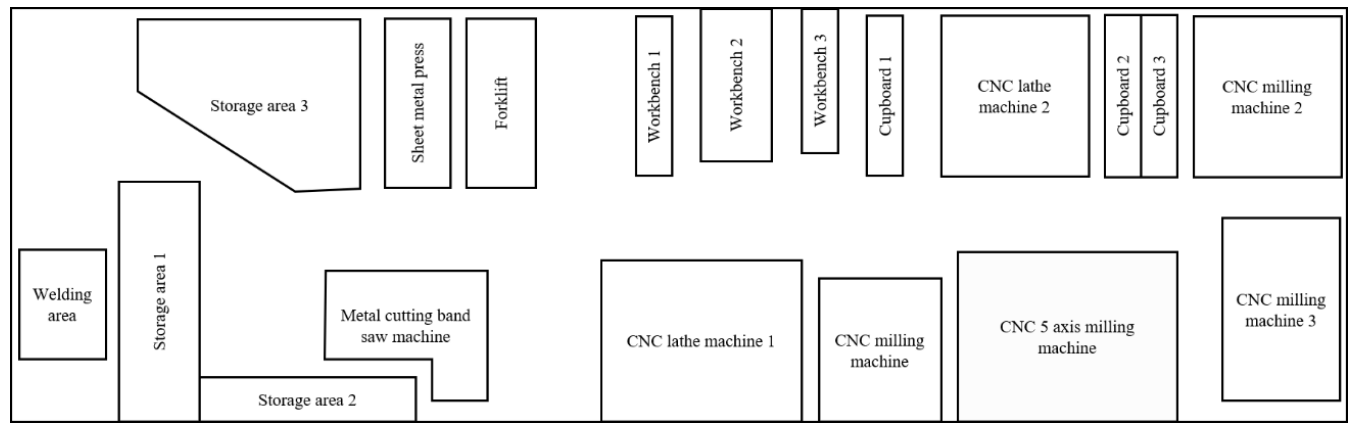

(b)

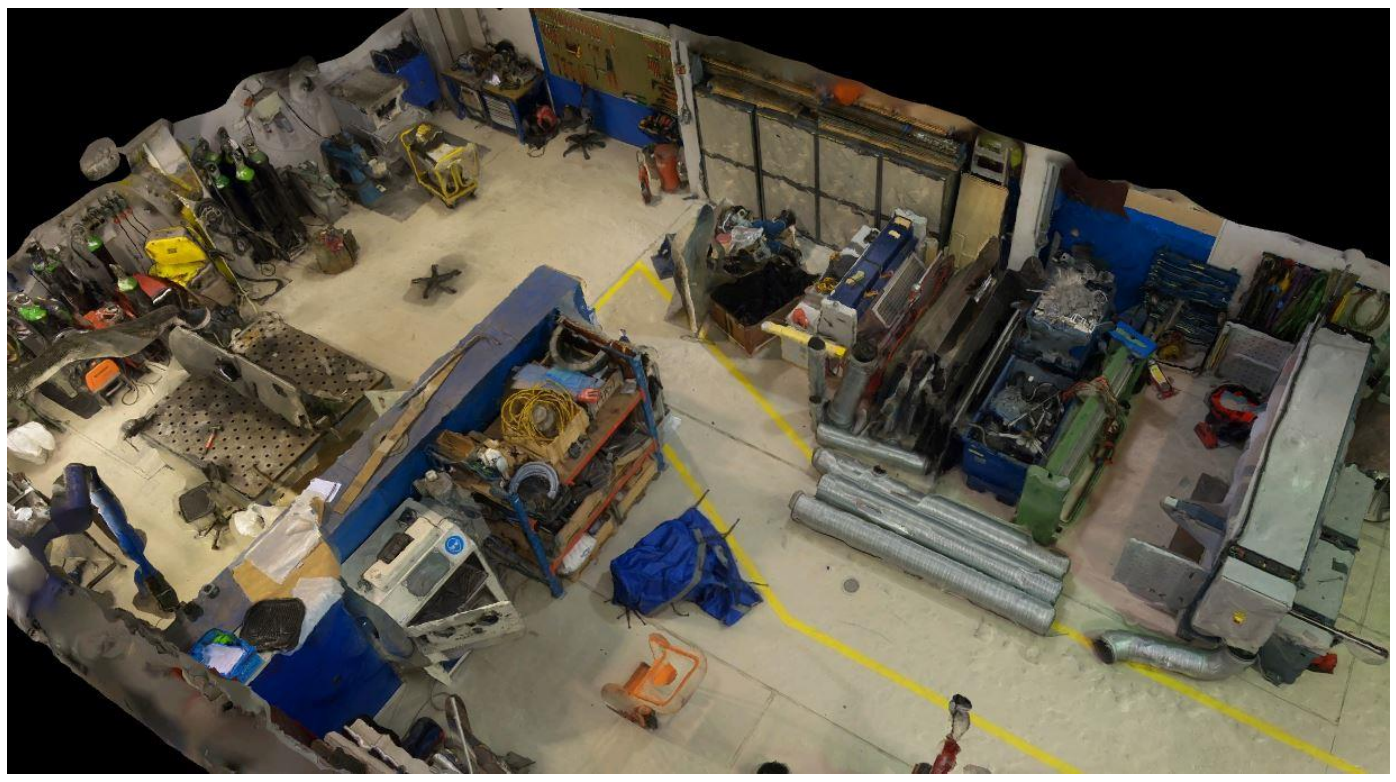

(c)

Figure 2. Machine level layout in the case of 3D mapping (a) and commonly used 2D drawing (b). Detail of 3D mapping (c).

IPS are instead attractive for step 1 and particularly for step 2 of the layout planning procedures at the three different levels (Table 2). In these two steps, information about the flow of materials/components/products are needed and are commonly based on the development of flow 
charts made by analysts who observe the process flow for a long period of time. Although this procedure is time-consuming, it lacks to provide fundamental information such as the occurrence of congestion phenomena. IPS technologies providing data-driven material flow analysis, can overcome this issue, specifying the location and the duration of such congestion phenomena, providing useful information to improve the material flow of the system. In addition, IPS can provide the real flow of the materials, not just their movement from A to B, but the real path covered by the material handling systems transporting them (Figure 3). In addition, the standard production flow based on the bill of materials or similar technique is improved considerably due to the capability of IPS technologies to determine the real flow between machines (Figure 3a), including possible reworks or use of alternative machines due to breakdown or unavailability. The result of IPS implementation in steps 1 and 2 is the data-driven relationship diagram.

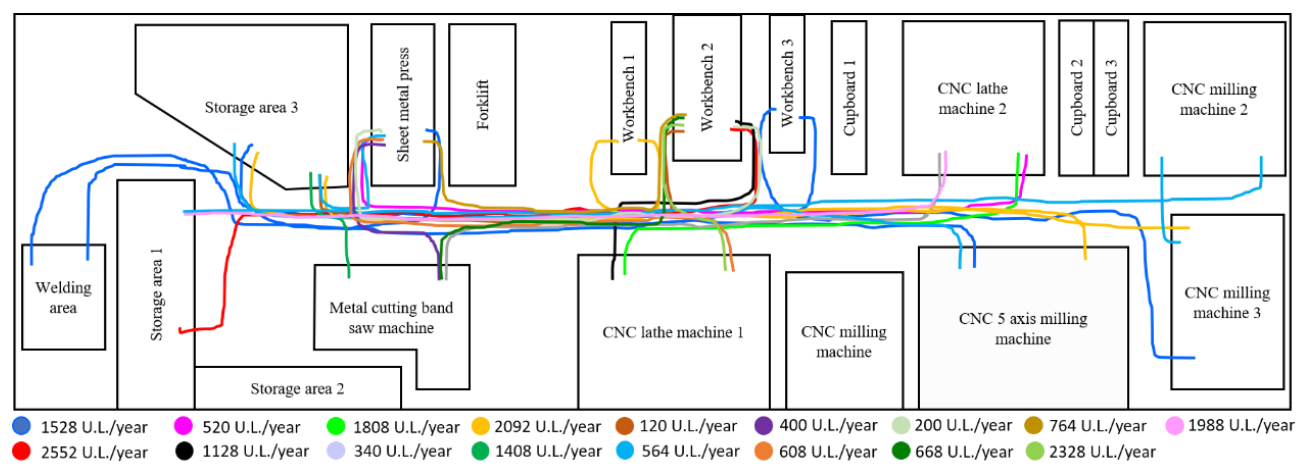

(a)

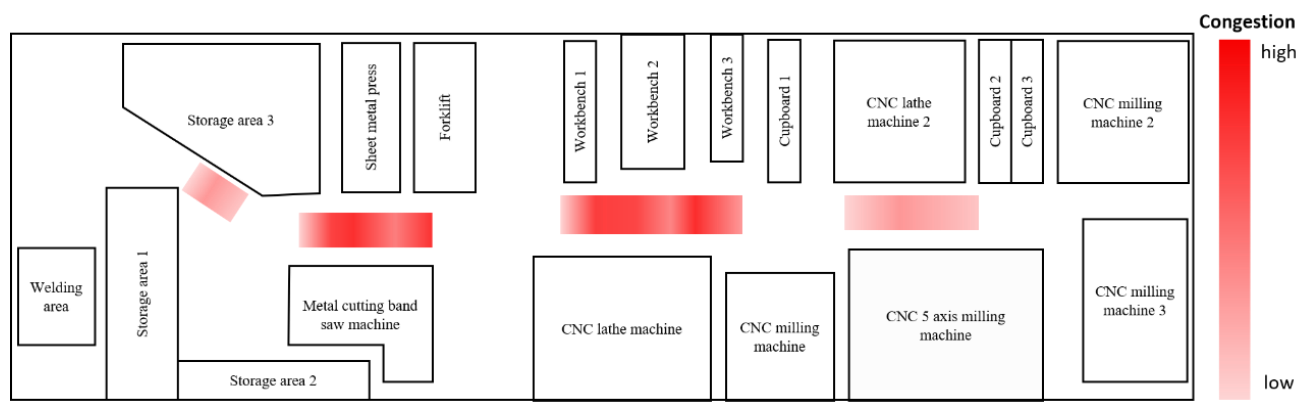

(b)

\begin{tabular}{|c|c|c|c|c|c|c|c|c|c|c|c|c|c|c|c|}
\hline & Ivelding & $\begin{array}{c}\text { storage } \\
\text { area } 1\end{array}$ & $\begin{array}{l}\text { storage } \\
\text { area } 3\end{array}$ & cutting & press & $\begin{array}{l}\text { CNC C } \\
\text { lathe 1 }\end{array}$ & $\begin{array}{c}\text { storage } \\
\text { area 2 }\end{array}$ & WB 1 & WB 2 & WB 3 & $\begin{array}{c}\mathrm{CNC} \\
\text { milling } 1\end{array}$ & $\begin{array}{c}\mathrm{CNC} \\
\text { lathe 2 }\end{array}$ & $\begin{array}{l}\mathrm{CNC} \\
5 \text { 5 axis } \\
\end{array}$ & $\begin{array}{c}\mathrm{CNC} \\
\text { milling }\end{array}$ & $\begin{array}{c}\mathrm{CNC} \\
\text { milling } 3\end{array}$ \\
\hline Twelding & & & & & & & & & & & & & 1528 & & \\
\hline $\begin{array}{l}\text { storagee } \\
\text { araea } 1\end{array}$ & & & & & & & & & & & & 1988 & 564 & & \\
\hline $\begin{array}{l}\text { Storage } \\
\text { araea } 3\end{array}$ & & & & 1408 & 564 & & & & 120 & & & & & & 2092 \\
\hline $\begin{array}{l}\text { antum } \\
\text { cutting }\end{array}$ & & & & & 400 & & & & 668 & & & 340 & & & \\
\hline $\begin{array}{l}\text { press } \\
\mathrm{CNC}\end{array}$ & 1528 & & & & 608 & & & & $\frac{764}{2328}$ & & & & & & \\
\hline $\begin{array}{l}\text { latat } 1 \\
\text { stora }\end{array}$ & & & & & & & & & & & & & & & \\
\hline & & & & & & & & & & & & & & & \\
\hline$\frac{\text { WB1 }}{\text { WB2 }}$ & & 2552 & 2092 & & 200 & 1128 & & & & & & & & & \\
\hline WB 3 & & & 1528 & & & & & & & & & & & & \\
\hline $\begin{array}{l}\text { CNC } \\
\text { milling } 1\end{array}$ & & & & & & & & & & & & & & & \\
\hline $\begin{array}{l}\text { CNCC } \\
\text { lathe2 }\end{array}$ & & & & & 520 & 1808 & & & & & & & & & \\
\hline 5 axis & & & & & & & & 2092 & & & & & & & \\
\hline $\begin{array}{c}\mathrm{CNC} \\
\mathrm{NN}\end{array}$ & & & 564 & & & & & & & & & & & & \\
\hline CNC & & & & & & & & & & 1528 & & & & 564 & \\
\hline ing 3 & & & & & & & & & & & & & & & \\
\hline
\end{tabular}

(c)

Figure 3. Available information about the flow of material when IPS is implemented (real flow of the material, a, congestion phenomena, b) and when traditional techniques are used (from-to cart in unit load/year, c). 
Finally, the implementation of MoCap and IR improves the Adjustment phase (step 4) of the workstation design. Usually, in the development of new workstations or in the improvement of existing ones, companies build several physical mock-ups where different layouts are proposed, and the interaction modalities of the operator with the workplace are evaluated. However, building physical mock-ups is both time-consuming and labor-intensive. These drawbacks can be easily overcome by the combination of MoCap and IR, where several workstation layouts can be virtually designed and evaluated. The use of such a system, in fact, allows one to evaluate a workstation without the need to build it physically in advance, by immersing the operator into the virtual environment (Figure 4a), reducing thus the time spent in this phase. Moreover, it is possible to perform real-time ergonomic evaluations thanks to the integration of a specific ergonomic assessment software with the motion capture system (Figure $4 \mathrm{~b}$ ). Figure 5 shows the contribution of the new technologies on the five-step layout planning procedures.
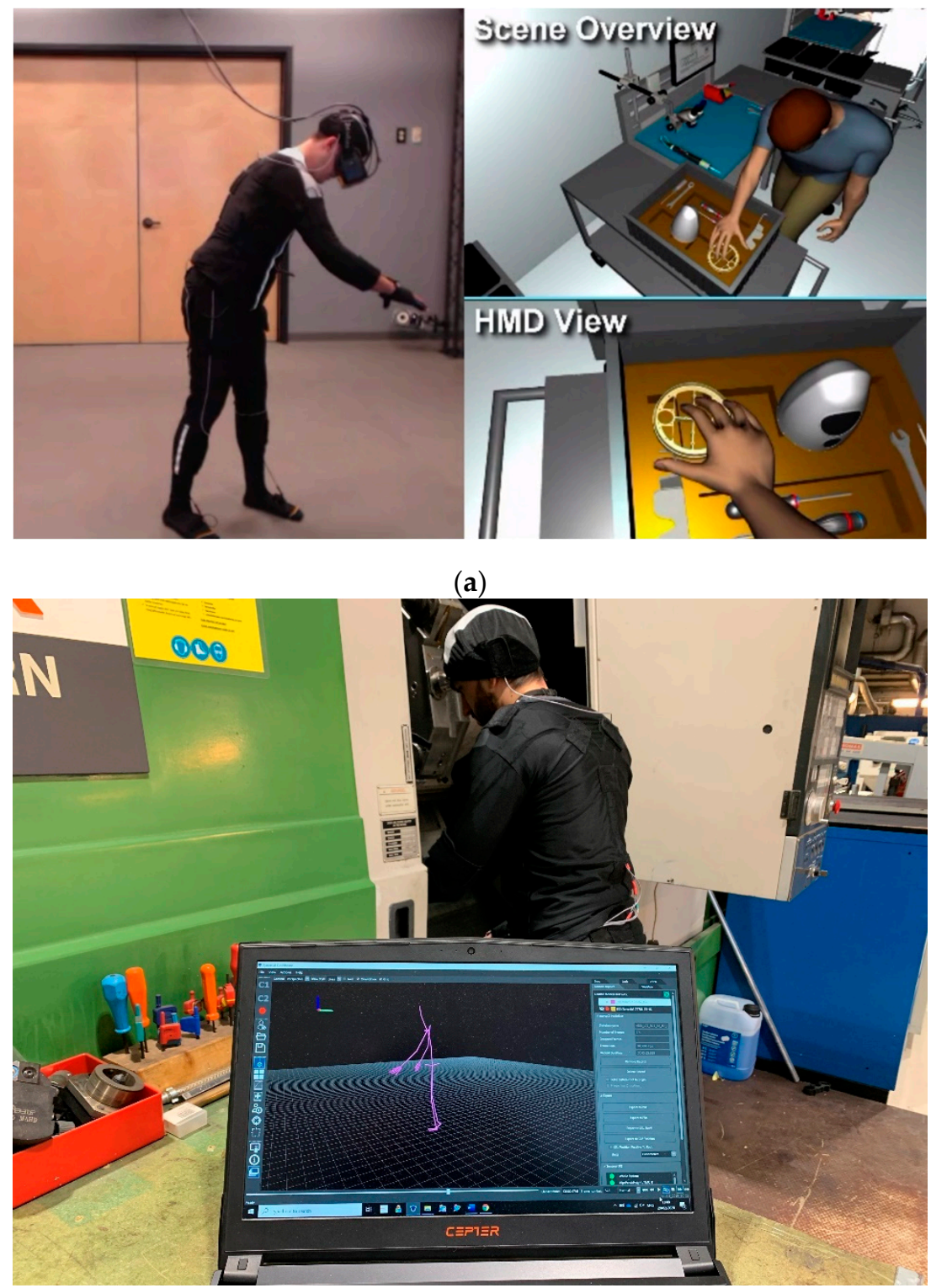

(b)

Figure 4. Combination of MoCap and IR [58] (a) and of MoCap and ergonomic assessment software (b). 


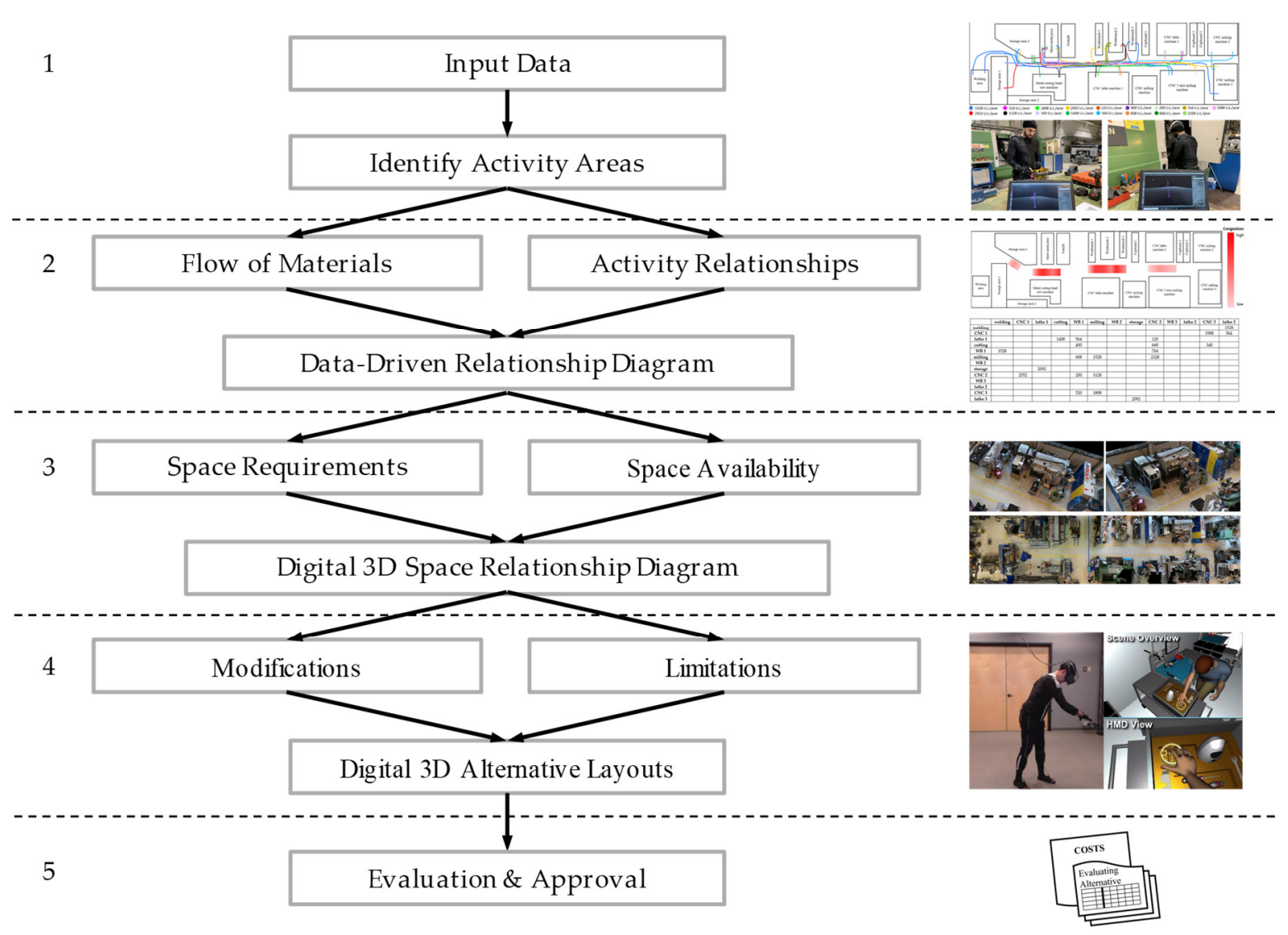

Figure 5. Innovative Layout Planning with digital tools.

\section{Discussion}

In recent years, companies are increasingly focusing on sustainability, not only from the narrow point of view of the environment but also from a social and economic perspective. The layout planning has so far represented one of the main limitations towards the achievement of this aim due to the static nature of the current layouts. Nowadays, in fact, layouts are designed for medium/long periods due to the related difficulties and time-consuming operations that hinder the achievement of dynamic layouts that represent the main requirement to achieve sustainable companies.

The introduction of emerging technologies such as 3D mapping, IPS, MoCap, and IR is beneficial for the transition from static layouts to dynamic layouts, and their impact on the three pillars constituting the sustainability concept is given in the details below and summarized in Table 3.

Table 3. Impact of the new technologies on the three pillars of sustainability.

\begin{tabular}{|c|c|c|}
\hline Economic Pillar & Social Pillar & Environmental Pillar \\
\hline $\begin{array}{l}\text { - Saved time and costs in all the } \\
\text { design procedures } \\
\text { - Reduced uncertainty and costly } \\
\text { errors due to wrong design } \\
\text { solution (no need to change } \\
\text { afterwards) } \\
\text { - Increased understanding and } \\
\text { better decision-making }\end{array}$ & $\begin{array}{l}\text { - Better ergonomics, less fatigue } \\
\text { - Adaptable workstations also for } \\
\text { older workforce } \\
\text { - More added value activities for } \\
\text { the designers of layout, they do } \\
\text { not need to spend time in } \\
\text { collecting info and they increase } \\
\text { their knowledge about the systems } \\
\text { they are designing }\end{array}$ & $\begin{array}{l}\text { - Use of the space efficient and so } \\
\text { less building of new facilities } \\
\text { - More compact means better use of } \\
\text { space, less transportation activities } \\
\text { - Optimal adaptable layout in case } \\
\text { of reconfigurable systems }\end{array}$ \\
\hline
\end{tabular}

3D mapping concurs to improve all the three pillars: the economic and the social ones by reducing the time and the costs associated with the gathering of the information related to space availability 
and equipment position, thus allowing the allocation of both economic and human resources to more added values activities, and by increasing the knowledge of the system under evaluation through the determination of connections/relationships between different areas and/or machines; the impact of 3D mapping on the environment is linked to the possibility to optimize the layout in a fast and easy way, thus enabling the continuous and constant reconfiguration of the system under consideration that leads to efficient use of the available space limiting the transportation activities and the need of new building facilities. To accomplish this goal, the combination of 3D mapping with IPS is essential because, by providing real-time and detailed information of the flow of material in the different levels (From-To chart, Relationship chart and Spaghetti chart in the department, machine and workstation level, respectively), it concurs to a better understanding of the system requirements and flaws, especially in terms of congestion phenomena. Finally, the combination of MoCap and IR impacts particularly on the economic and social pillars, and their benefits are notably evident in the workstation level where the design of workstations can be optimized taking into consideration the operators' needs, and extremely reduced in terms of time and resources (economic and human) allocated to the related operations. In fact, by virtualizing the conceptualization and development of the workstations, the realization and assessment of different physical workstation mockups are no longer required, saving time and money. The choice to virtualize the development and testing of the different mockup solutions also impacts the environment since less material needs to be wasted to physically build the mockup, and also less transportation is required. The decision-makers can thus base their alternatives evaluation and final choice on the traditional Key Performance Indicators (KPIs), well-established and widely used in the layout planning procedure. The main difference is that those KPIs are now estimated using more accurate data and information about material flows, space requirements, space and equipment constraints, and others.

The implementation of such technologies could be useful to industries that are continuously faced with the need to redesign their layout due to the introduction of new products and/or the modification of the throughput of the systems as a consequence of market changes. This is particularly relevant for all the industries involved in the supply chain of products that are subjected to the variability of the market. While the modification of the throughput mainly acts on the department and machine level of the layout planning, the introduction of new products affects all the three levels. Companies are thus required to understand whether implementing these technologies may be profitable, and to do so, the need for some easily applicable cost models and/or decision support systems is arising. While the development of such tools for the economic pillar is of easy conceptualization and formulation, it is more difficult to correctly and coherently evaluate their impact on social and environmental pillars, rendering it an aspect that needs to be investigated and solved to consider the potential of these technologies for all the aspects. Finally, for the achievement of fully dynamic layouts, the introduction of the new technologies should be accompanied by the integration of the new technologies with dedicated systems and software that use the data from the new technologies as input for simulations to carry out final adjustment and evaluations. In particular, the evaluations should concern all the three pillars and be constantly updated by the collection of empirical data for further and continuous improvements.

\section{Conclusions}

In this paper, the introduction of the technologies of 3D mapping, IPS, MoCap, and IR in the layout planning has been evaluated, with a special focus on their impact in the development of sustainable facilities. In particular, the effects of the emerging technologies on the three pillars constituting the sustainability concept, namely environmental, social, and economic, has been assessed, allowing the following conclusions:

- All the technologies herein considered reduce the time efforts, error rates and costs involved in the five-step layout planning procedures on the department, machine, and workstation level 
- MoCap and IR are particularly attractive considering the social pillar since they allow to pursue a human-centered design of the workstation that improves the ergonomic of the workers and reduces their fatigue

- An optimal and dynamic layout in both the department and machine level impact the environment with a reduced need for new buildings and transportation activities

The introduction of new technologies is, thus, of great interest and worthy of further investigation of its potential role in the development of sustainable facilities. Most importantly, the future integration with dedicated software will allow constant monitoring of the sustainability performances of the layout, permitting the development of fully dynamic layouts.

However, the function and effectiveness of these technologies and their spatial-dependent applications (whether in the virtual or in the physical space) inevitably depends on the complexity of the spatial data that are used in the applications. This is because the spatial complexity [9] influences the level of spatial detail upon which technologies perform, and this aspect has to be further analyzed. Finally, future research should investigate the research opportunities to develop and analyze data-driven key performance indicators and to investigate their potential use in relation to the applied technologies and industrial application (like process industry, discrete manufacturing, warehouses, etc.).

Author Contributions: Conceptualization, M.P., G.F. and F.S.; methodology, M.P., G.F., F.S. and M.K.; validation, M.P. and G.F.; formal analysis, M.P., G.F. and F.S.; data curation, M.P.; writing-original draft preparation, M.P., G.F., F.S. and M.K.; writing—review and editing, M.K.; supervision, F.S. All authors have read and agree to the published version of the manuscript.

Funding: This research received no external funding.

Conflicts of Interest: The authors declare no conflict of interest.

\section{References}

1. Armour, G.C.; Buffa, E.S. Heuristic algorithm and simulation approach to relative location of facilities. Manag. Sci. 1963, 9, 171-349. [CrossRef]

2. Shubin, J.A.; Madeheim, H. Plant Layout: Developing and Improving Manufacturing Plants—John A. Shubin, Huxley Madeheim—Google Books; Prentice-Hall: New York, NY, USA, 1951.

3. Drira, A.; Pierreval, H.; Hajri-Gabouj, S. Facility layout problems: A survey. Annu. Rev. Control 2007, 31, 255-267. [CrossRef]

4. Ahmadi, A.; Pishvaee, M.S.; Akbari Jokar, M.R. A survey on multi-floor facility layout problems. Comput. Ind. Eng. 2017, 107, 158-170. [CrossRef]

5. Attri, R.; Grover, S. Modelling the quality enabled factors of facility layout design stage of production system life cycle. Int. J. Syst. Assur. Eng. Manag. 2017, 8, 413-423. [CrossRef]

6. Hosseini-Nasab, H.; Fereidouni, S.; Fatemi Ghomi, S.M.T.; Fakhrzad, M.B. Classification of facility layout problems: A review study. Int. J. Adv. Manuf. Technol. 2018, 94, 957-977. [CrossRef]

7. Zhu, T.; Balakrishnan, J.; Cheng, C.H. Recent advances in dynamic facility layout research. INFOR 2018, 56, 428-456. [CrossRef]

8. Boysen, N.; de Koster, R.; Weidinger, F. Warehousing in the e-commerce era: A survey. Eur. J. Oper. Res. 2019, 277, 396-411. [CrossRef]

9. Papadimitriou, F. Modelling spatial landscape complexity using the Levenshtein algorithm. Ecol. Inform. 2009, 4, 48-55. [CrossRef]

10. Hansmann, R.; Mieg, H.A.; Frischknecht, P. Principal sustainability components: Empirical analysis of synergies between the three pillars of sustainability. Int. J. Sustain. Dev. World Ecol. 2012, 19, 451-459. [CrossRef]

11. Carter, C.R.; Rogers, D.S. A framework of sustainable supply chain management: Moving toward new theory. Int. J. Phys. Distrib. Logist. Manag. 2008, 38, 360-387. [CrossRef]

12. Henriques, A.; Richardson, J. The Triple Bottom Line: Does It All Add Up? Routledge: Oxfordshire, UK, 2004; ISBN 1136551689. 
13. Tak, C.S.; Lalit Yadav, M. Improvement in Layout Design using SLP of a small size manufacturing unit: A case study. IOSR J. Eng. 2012, 2, 1-7. [CrossRef]

14. Muther, R.; Hales, L. Systematic Layout Planning, Fourth Edition; Management and Industrial Research Publications: Marietta, GA, USA, 2015.

15. Marcoux, N.; Riopel, D.; Langevin, A. Models and methods for facilities layout design from an applicability to real-world perspective. In Logistics Systems: Design and Optimization; Springer: Berlin, Germany, 2005; pp. 123-170.

16. Heragu, S.S. Facilities Design; CRC Press: Boca Raton, FL, USA, 2016; ISBN 9781498732895.

17. Singh, S.P.; Sharma, R.R.K. A review of different approaches to the facility layout problems. Int. J. Adv. Manuf. Technol. 2006, 30, 425-433. [CrossRef]

18. El-Hakim, S.; Remondino, F. Image-based 3D Modelling: A Review. Photogramm. Rec. 2006, 21, $269-291$.

19. Luhmann, T. Close range photogrammetry for industrial applications. ISPRS J. Photogramm. Remote Sens. 2010, 65, 558-569. [CrossRef]

20. Boesemann, W.; Godding, R.; Huette, H. Photogrammetric measurement techniques for quality control in sheet metal forming. In Proceedings of the Archives of Photogrammetry, Remote Sensing and Spatial Information Science, Amsterdam, The Nerthlands, 16-22 July 2000.

21. Wang, J.; Sun, W.; Shou, W.; Wang, X.; Wu, C.; Chong, H.Y.; Liu, Y.; Sun, C. Integrating BIM and LiDAR for Real-Time Construction Quality Control. J. Intell. Robot. Syst. Theory Appl. 2015, 79, 417-432. [CrossRef]

22. Puente, I.; González-Jorge, H.; Martínez-Sánchez, J.; Arias, P. Review of mobile mapping and surveying technologies. Meas. J. Int. Meas. Confed. 2013, 46, 2127-2145. [CrossRef]

23. Gu, Y.; Lo, A.; Niemegeers, I. A survey of indoor positioning systems for wireless personal networks. IEEE Commun. Surv. Tutor. 2009, 11, 13-32. [CrossRef]

24. Tesoriero, R.; Gallud, J.; Lozano, M.; Penichet, V. Using active and passive RFID technology to support indoor location-aware systems. IEEE Trans. Consum. Electron. 2008, 54, 578-583. [CrossRef]

25. Zuin, S.; Calzavara, M.; Sgarbossa, F.; Persona, A. Ultra Wide Band Indoor Positioning System: Analysis and testing of an IPS technology. IFAC-PapersOnLine 2018, 51, 1488-1492.

26. Curran, K.; Furey, E.; Lunney, T.; Santos, J.; Woods, D.; McCaughey, A. An evaluation of indoor location determination technologies. J. Locat. Based Serv. 2011, 5, 61-78. [CrossRef]

27. Kaemarungsi, K.; Krishnamurthy, P. Properties of indoor received signal strength for WLAN location fingerprinting. In Proceedings of the The First Annual International Conference on Mobile and Ubiquitous Systems: Networking and Services, Boston, MA, USA, 26 August 2004; IEEE: Piscataway, NJ, USA, 2004; pp. 14-23.

28. Hightower, J.; Borriello, G. Location Sensing Techniques; University of Washington: Seattle, WA, USA, 2001.

29. Deak, G.; Curran, K.; Condell, J. A survey of active and passive indoor localisation systems. Comput. Commun. 2012, 35, 1939-1954. [CrossRef]

30. Liang, J.Z.; Corso, N.; Turner, E.; Zakhor, A. Image Based Localization in Indoor Environments. In Proceedings of the 2013 Fourth International Conference on Computing for Geospatial Research and Application, San Jose, CA, USA, 22-24 July 2013; IEEE: Piscataway, NJ, USA, 2013; pp. 70-75.

31. Mainetti, L.; Patrono, L.; Sergi, I. A survey on indoor positioning systems. In Proceedings of the 2014 22nd International Conference on Software, Telecommunications and Computer Networks (SoftCOM), Split, Croatia, 17-19 September 2014; IEEE: Piscataway, NJ, USA, 2014; pp. 111-120.

32. Fernando, X.N.; Krishnan, S.; Sun, H.; Kazemi-Moud, K. Adaptive Denoising at Infrared Wireless Receivers; Andresen, B.F., Fulop, G.F., Eds.; International Society for Optics and Photonics: Bellingham, WA, USA, 2003; Volume 5074, p. 199.

33. Chen, L.-H.; Wu, E.H.-K.; Jin, M.-H.; Chen, G.-H. Intelligent Fusion of Wi-Fi and Inertial Sensor-Based Positioning Systems for Indoor Pedestrian Navigation. IEEE Sens. J. 2014, 14, 4034-4042. [CrossRef]

34. Ni, L.M.; Liu, Y.; Lau, Y.C.; Patil, A.P. LANDMARC: Indoor location sensing using active RFID. In Proceedings of the First IEEE International Conference on Pervasive Computing and Communications, Fort Worth, TX, USA, 26 March 2003; pp. 407-415.

35. Battaïa, O.; Otto, A.; Sgarbossa, F.; Pesch, E. Future trends in management and operation of assembly systems: From customized assembly systems to cyber-physical systems. Omega 2018, 78, 1-4. [CrossRef]

36. Pine, B.J. Mass Customization: The New Frontier in Business Competition; Harvard Business School Press: Cambridge, MA, USA, 1993; ISBN 0875843727. 
37. Zennaro, I.; Finco, S.; Battini, D.; Persona, A. Big size highly customised product manufacturing systems: A literature review and future research agenda. Int. J. Prod. Res. 2019, 57, 5362-5385. [CrossRef]

38. Gonzalez, I.; Morer, P. Ergonomics for the inclusion of older workers in the knowledge workforce and a guidance tool for designers. Appl. Ergon. 2016, 53, 131-142. [CrossRef]

39. Calzavara, M.; Battini, D.; Bogataj, D.; Sgarbossa, F.; Zennaro, I. Ageing workforce management in manufacturing systems: State of the art and future research agenda. Int. J. Prod. Res. 2020, 58, 729-747. [CrossRef]

40. Brinzer, B.; Banerjee, A. Measuring the Human Aspect: The Key for Managing the Complexity in Production; Springer: Berlin, Germany, 2018; pp. 14-24.

41. Dul, J.; Neumann, W.P. Ergonomics contributions to company strategies. Appl. Ergon. 2009, 40, 745-752. [CrossRef]

42. Battini, D.; Faccio, M.; Persona, A.; Sgarbossa, F. New methodological framework to improve productivity and ergonomics in assembly system design. Int. J. Ind. Ergon. 2011, 41, 30-42. [CrossRef]

43. Battini, D.; Persona, A.; Sgarbossa, F. Innovative real-time system to integrate ergonomic evaluations into warehouse design and management. Comput. Ind. Eng. 2014, 77, 1-10. [CrossRef]

44. Otto, A.; Battaïa, O. Reducing physical ergonomic risks at assembly lines by line balancing and job rotation: A survey. Comput. Ind. Eng. 2017, 111, 467-480. [CrossRef]

45. Otto, A.; Boysen, N.; Scholl, A.; Walter, R. Ergonomic workplace design in the fast pick area. OR Spectr. 2017, 39, 945-975. [CrossRef]

46. Vignais, N.; Miezal, M.; Bleser, G.; Mura, K.; Gorecky, D.; Marin, F. Innovative system for real-time ergonomic feedback in industrial manufacturing. Appl. Ergon. 2013, 44, 566-574. [CrossRef] [PubMed]

47. Vignais, N.; Bernard, F.; Touvenot, G.; Sagot, J.-C. Physical risk factors identification based on body sensor network combined to videotaping. Appl. Ergon. 2017, 65, 410-417. [CrossRef] [PubMed]

48. Puthenveetil, S.C.; Daphalapurkar, C.P.; Zhu, W.; Leu, M.C.; Liu, X.F.; Gilpin-Mcminn, J.K.; Snodgrass, S.D. Computer-automated ergonomic analysis based on motion capture and assembly simulation. Virtual Real. 2015, 19, 119-128. [CrossRef]

49. Faccio, M.; Gamber, M.; Piana, F.; Pilati, F. Motion analysis system for the ergonomic assessment of manufacturing and assembly manual activities. In Proceedings of the Proceedings of XXII Summer School "Francesco Turco", Palermo, Italy, 13-15 September 2017.

50. Lawson, G.; Salanitri, D.; Waterfield, B. Future directions for the development of virtual reality within an automotive manufacturer. Appl. Ergon. 2016, 53, 323-330. [CrossRef]

51. Grajewski, D.; Górski, F.; Hamrol, A.; Zawadzki, P. Immersive and Haptic Educational Simulations of Assembly Workplace Conditions. Procedia Comput. Sci. 2015, 75, 359-368. [CrossRef]

52. Grajewski, D.; Górski, F.; Zawadzki, P.; Hamrol, A. Application of Virtual Reality Techniques in Design of Ergonomic Manufacturing Workplaces. Procedia Comput. Sci. 2013, 25, 289-301. [CrossRef]

53. Gavish, N.; Gutiérrez, T.; Webel, S.; Rodríguez, J.; Peveri, M.; Bockholt, U.; Tecchia, F. Evaluating virtual reality and augmented reality training for industrial maintenance and assembly tasks. Interact. Learn. Environ. 2015, 23, 778-798. [CrossRef]

54. Caputo, F.; Greco, A.; D’Amato, E.; Notaro, I.; Spada, S. A Preventive Ergonomic Approach Based on Virtual and Immersive Reality; Springer: Berlin, Germany, 2018; pp. 3-15.

55. Vosniakos, G.-C.; Deville, J.; Matsas, E. On Immersive Virtual Environments for Assessing Human-driven Assembly of Large Mechanical Parts. Procedia Manuf. 2017, 11, 1263-1270. [CrossRef]

56. Peruzzini, M.; Pellicciari, M.; Gadaleta, M. A comparative study on computer-integrated set-ups to design human-centred manufacturing systems. Robot. Comput. Integr. Manuf. 2019, 55, 265-278. [CrossRef]

57. Battini, D.; Calzavara, M.; Persona, A.; Sgarbossa, F.; Visentin, V.; Zennaro, I. Integrating mocap system and immersive reality for efficient human-centred workstation design. IFAC-PapersOnLine 2018, 51, 188-193.

58. AiQ Synertial. Leading Motion Capture Technologies. Available online: https://www.synertial.com/ (accessed on 7 March 2020).

(C) 2020 by the authors. Licensee MDPI, Basel, Switzerland. This article is an open access article distributed under the terms and conditions of the Creative Commons Attribution (CC BY) license (http://creativecommons.org/licenses/by/4.0/). 